\title{
Preparation and Characterization of Montmorillonite Intercalation Compounds with Quaternary Ammonium Surfactant: Adsorption Effect of Zearalenone
}

\author{
Yujin Li, ${ }^{1}$ Lu Zeng, ${ }^{2}$ Yan Zhou, ${ }^{1}$ Tiefu Wang, ${ }^{1}$ and Yanji Zhang ${ }^{1}$ \\ ${ }^{1}$ College of Earth Sciences, Jilin University, Changchun 130000, China \\ ${ }^{2}$ College of Materials Science and Engineering, Chongqing University, Chongqing 400030, China \\ Correspondence should be addressed to Lu Zeng; zool@foxmail.com
}

Received 24 September 2013; Accepted 14 December 2013; Published 9 February 2014

Academic Editor: Sun-Hwa Yeon

Copyright (C) 2014 Yujin Li et al. This is an open access article distributed under the Creative Commons Attribution License, which permits unrestricted use, distribution, and reproduction in any medium, provided the original work is properly cited.

\begin{abstract}
Montmorillonite (Mt) was used as the original material to prepare intercalation compounds with quaternary ammonium surfactant (QAS). The adsorption of zearalenone (ZEA) onto Mt and organomodified Mt was investigated in vitro. Effects of QAS in binding ZEA were studied. By the method of intercalation with dioctadecylmethylbenzylammonium chloride (DOMBAC), the sample exhibited the highest adsorption rate of ZEA (93.2\%) which was much higher than that of Mt (10.5\%). Several methods were adopted to characterize samples, including XRD, TG/DSC, $\mathrm{N}_{2}$ adsorption/desorption, and FTIR. Adsorption isotherm parameters were obtained from Langmuir and Freundlich and the adsorption data fitted better to Langmuir. All results indicate that organomodified Mt has great potential to be a high-performance material to control ZEA contamination.
\end{abstract}

\section{Introduction}

Many types of clay minerals such as montmorillonite (Mt), sepiolite, and kaolinite have shown high adsorption capacity. Mt, a clay mineral with 2:1 layered structure, can hold some cations between its layers. Substitution of $\mathrm{Si}^{4+}$ with $\mathrm{Al}^{3+}$ in tetrahedral sheets and $\mathrm{Al}^{3+}$ with $\mathrm{Mg}^{2+}$ in octahedral sheets make the lattice a net negative charge which is usually balanced by cations of $\mathrm{Li}^{+}, \mathrm{Na}^{+}$, and $\mathrm{Ca}^{2+}$ located between the layers. These cations can be easily replaced by other organic or inorganic cations under certain conditions, which endow Mt with some special properties [1]. Mt has been widely used in industry and agriculture, particularly in adsorption of mycotoxins. According to the Food and Agriculture Organization (FAO), 25\% of the world's cereal grain production is contaminated by mycotoxins [2]. Zearalenone (ZEA), along with others most of mycotoxins, commonly found in animal feeds, can cause serious health problems in livestock [3,4]. Zearalenone is most notorious for its effects on precocious development of mammae and other estrogenic effects in young gilts [5]. The chemical structure of ZEA is presented in Figure 1 [6]. It has been reported that natural Mt are effective in adsorbing aflatoxins in vitro and in vivo $[7,8]$. However, their hydrophilic negatively charged surfaces are less effective in binding other mycotoxins, which are more hydrophobic, such as ZEA. According to some literatures, organic modification of clays with organic cations, surfactants, can result in high affinity for in vitro adsorption of hydrophobic ZEA [4-9].

The quaternary ammonium surfactant (QAS) is the most commonly used organic modifier, which can enhance the lipophilicity of Mt. However, QAS contains many different kinds such as the types with short carbochain, medium carbochain, long carbochain, and double carbochain and the type with functional group of benzyl. In this study, Mt intercalation compounds with QAS were prepared and characterized; the adsorption effect of ZEA onto adsorbents was compared. The objective of the research is to investigate 


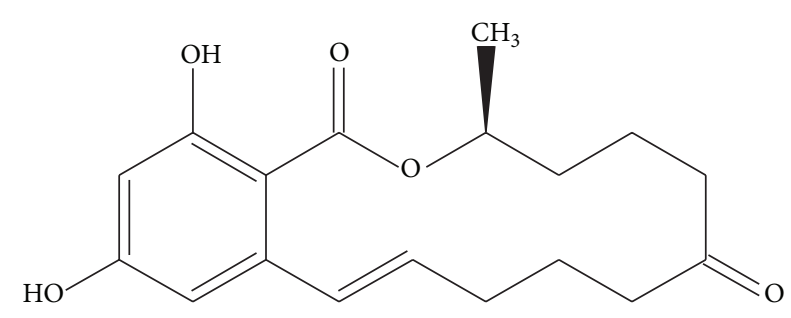

FIGURE 1: The molecular structural formula of ZEA.

the adsorption of ZEA onto Mt intercalation compounds with QAS and explore the optimum QAS in binding ZEA. To the best of our knowledge similar research has not been reported.

\section{Materials and Methods}

2.1. Preparation and Characterization of Mt. Mt, the original materials supplied by Sanding Company, consists of a lot of $\mathrm{Mt}$ and a small amount of quartz, according to powder X-ray diffraction (XRD) analysis shown in Figure 2. The primary ion in the exchangeable position is sodium and the cation exchange capacity of $\mathrm{Mt}$ is $1.44 \mathrm{mmol} / \mathrm{g}$ [10]. Mt was dried at $80^{\circ} \mathrm{C}$ to constant mass and then milled to less than $45 \mu \mathrm{m}$. QAS, supplied by Daochun Company, includes dodecyltrimethylammonium chloride (DTAC), octadecyltrimethylammonium chloride (OTAC), behenyltrimethylammonium chloride (BTAC), dodecyldimethylbenzylammonium chloride (DDBAC), octadecyldimethylbenzylammonium chloride (ODBAC), and dioctadecylmethylbenzylammonium chloride (DOMBAC), and the corresponding organomodified $\mathrm{Mt}$ is MDTAC, MODAC, MBTAC, MDDBAC, MODBAC, and MDOMBAC, respectively. The molecular structural formulas of QAS are shown in Table 1.

For preparation of organomodified Mt, which was synthesized by interaction (cation exchange) of Mt with OAS, Mt reacted with $1.44 \mathrm{mmol} / \mathrm{g}$ QAS at $90^{\circ} \mathrm{C}$ in distilled water, mixing speed $200 \mathrm{rpm}$ for $1 \mathrm{~h}$, according to the procedure described previously [11]. When the reaction was over, the suspensions were centrifuged and washed by distilled water for several times and dried at $80^{\circ} \mathrm{C}$ to constant mass and then milled to less than $45 \mu \mathrm{m}$. The effect of different kinds of QAS on the adsorption of ZEA was investigated according to the adsorption capacity of ZEA.

Samples were characterized by X-ray powder diffraction (XRD) analysis, thermogravimetric/differential scanning calorimetry analysis (TG/DSC), $\mathrm{N}_{2}$ adsorption/desorption, and Fourier transform infrared spectroscopy (FTIR) analysis. XRD analysis was performed on a Rigaku D/max-3Bx diffractometer with $\mathrm{Cu} \mathrm{K} \alpha$ radiation, in the range of $50-70^{\circ}$ $2 \theta$ and a step of $0.02^{\circ}$. TG/DSC analysis was performed on a STA 409 thermal analysis instrument, from $25^{\circ} \mathrm{C}$ (room temperature) to $1200^{\circ} \mathrm{C}$ and with heating rate of $10^{\circ} \mathrm{C} / \mathrm{min}$. Brunauer-Emmet-Teller (BET) specific surface area $\left(S_{\mathrm{BET}}\right)$, total pore volumes $\left(V_{\text {total }}\right)$, and average pore diameter $\left(D_{p}\right)$ of the samples were measured from $\mathrm{N}_{2}$ adsorption/desorption isotherms at $77 \mathrm{~K}$, using an automatic specific surface area

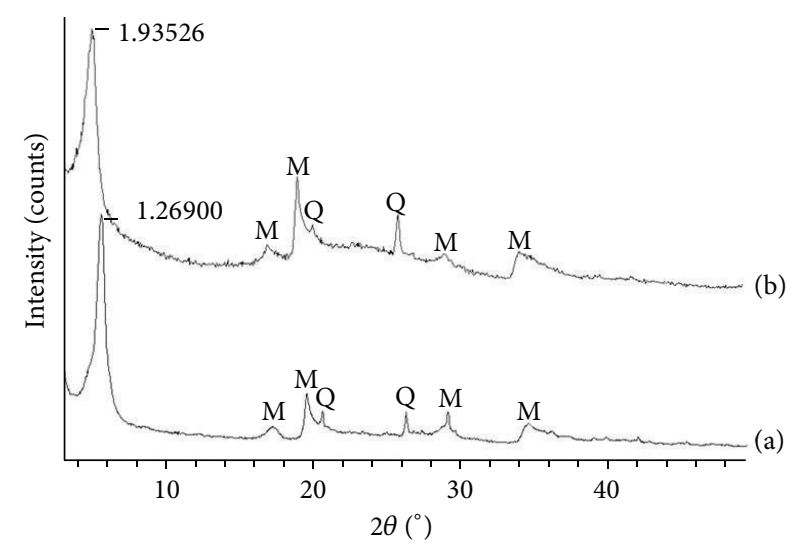

M: Montmorillonite

Q: Quartz

FIGURE 2: XRD patterns of (a) Mt and (b) MDOMBAC.

measuring equipment (ASAP, 2020M, USA) after a degassing under vacuum for $8 \mathrm{~h}$ at $110^{\circ} \mathrm{C}$. Infrared spectra were recorded by means of Thermoelectron FTIR spectrometer (Avatar370) in the range of $4000-400 \mathrm{~cm}^{-1}$.

2.2. Adsorption Experiments. The method of enzyme linked immunosorbent assay (ELISA) was adopted to measure the amount of ZEA which was purchased from Sigma-Aldrich Co., and ELISA kits were purchased from R-Biopharm Co. Firstly, ZEA stock solution $(4 \mu \mathrm{g} / \mathrm{mL})$ was prepared, then $10 \mathrm{mg}$ of organomodified Mt was added to tube that was filled with $10 \mathrm{~mL}$ ZEA solution $(4 \mu \mathrm{g} / \mathrm{mL})$ whose $\mathrm{pH}$ was adjusted to 2 by adding $0.1 \mathrm{M}$ phosphate buffer as required. After $1 \mathrm{~h}$ reaction at $37^{\circ} \mathrm{C}$ in temperature-controlled shaking water bath pot at a shaking rate of $120 \mathrm{rpm}$, the tube was centrifuged for $10 \mathrm{~min}$ at $5000 \mathrm{rpm}$ and then the amount of ZEA remaining in the supernatant layer of suspension was analyzed with the method of ELISA. The adsorption capacities were calculated from the difference between initial and equilibrium concentrations of ZEA. For isotherm study, $\mathrm{Mt}(10 \mathrm{mg})$ was added to $10 \mathrm{~mL}$ ZEA solution $\left(\mathrm{pH}=2,37^{\circ} \mathrm{C}\right)$ at different concentrations $(0.25,0.5,1.0,2.0,4.0$, and $6.0 \mu \mathrm{g} / \mathrm{mL}$ resp.) and so was organomodified Mt but with increased concentrations of ZEA solution (1.0, 2.0, 4.0, 6.0, 8.0, and $10.0 \mu \mathrm{g} / \mathrm{mL}$, resp.) due to its higher adsorbance of ZEA. The adsorption data were fitted to the models of Langmuir and Freundlich isotherm.

\section{Results and Discussion}

3.1. Effects of QAS. As can be seen from Table 1, Mt is quite ineffective in adsorbing ZEA (10.5\%) due to its poor lipophilicity and different kinds of QAS can draw significantly different influences on the adsorption of ZEA. For QAS without benzyl, the type with medium carbochain is beneficial to the adsorption of ZEA because MOTAC obtains the maximum adsorbance of ZEA (45.8\%), which is higher than that of MDTAC (24.7\%) and MBTAC (36.5\%). The 
TABLE 1: Effects of QAS on the adsorbance of ZEA on adsorbents.

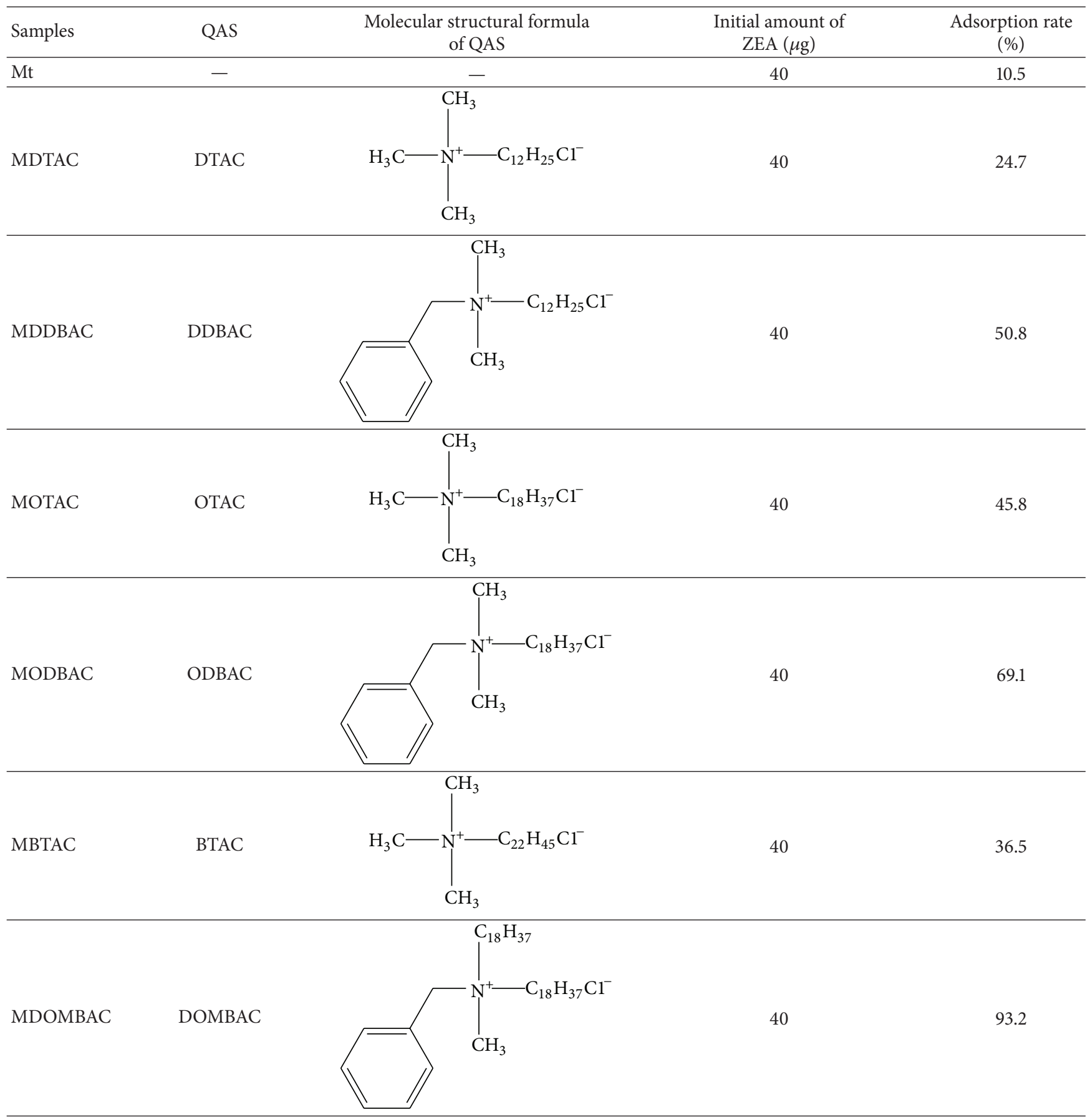

result is attributed to that the lipophilicity of MOTAC with longer carbochain is higher than that of MDTAC, but when the carbochain is too long, it is hard for the intercalation reaction which is adverse to the organic modification [12]. Moreover, the influence of intercalation reaction on pore size of adsorbent has two completely opposite effects [13]: the "pore blockage" effect, organic molecules fill pores and result in the decrease of pore size and $S_{\mathrm{BET}}$, and the "pore prop" effect, macromolecular organics insert into the interlayer and cause the distraction of aluminosilicate layer and the increase of pore size and $S_{\mathrm{BET}}$. Hence, the molecule sizes of QAS have great influences on the absorption capacity of adsorbents. Meanwhile, benzyl group has great influences on the adsorption of ZEA, which can significantly increase the adsorbance of ZEA on adsorbents. Herein, the adsorbance of ZEA on MDDBAC (50.8\%) and MODBAC (69.1\%) is higher than that of MDTAC and MOTAC, respectively. It can be attributed to that the critical effect of benzyl ring into the interlamellar space of Mt greatly enhances the penetration of QAS, which results in a better effect of modification; besides, 


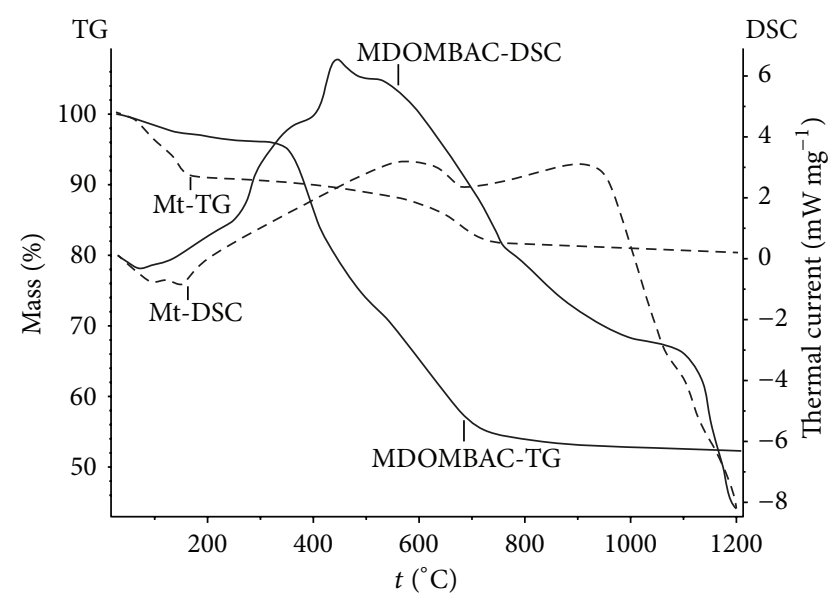

Figure 3: TG/DSC curves of Mt and MDOMBAC.

benzyl is beneficial to the increase of lipophilicity [14]. Furthermore, MDOMBAC has higher adsorption capacity of ZEA (93.2\%) than that of MODBAC, which is the maximum in all of the organomodified $\mathrm{Mt}$, indicating that optimal QAS with double medium carbochain and benzyl group does favor the adsorption of ZEA onto adsorbent. The result obtained shows that QAS plays an important role in binding ZEA and it can be attributed to the physicochemical property of QAS which has influences on the dispersion and lipophilicity of organomodified Mt [15-17].

3.2. XRD Characterization. XRD patterns reveal the microstructure variety of samples. The comparative XRD patterns of $\mathrm{Mt}$ and MDOMBAC are presented in Figure 2. It shows that the $\mathrm{d}_{001}$ values of $\mathrm{Mt}$ and MDOMBAC are 1.26900 and $1.93526 \mathrm{~nm}$, respectively, indicating that $\mathrm{Mt}$ is intercalated by dioctadecylmethylbenzylammonium (DOMBA) ions because the radius of DOMBA ions is larger than that of sodium ion [18]. Besides, there is no significant difference between their patterns, indicating that the basic structure of Mt is not changed. By the way of organic intercalation, MDOMBAC can obtain greater surface area and become more porous theoretically, which can improve its adsorption ability of ZEA greatly [19]. Therefore, the adsorption capacity of ZEA on MDOMBAC is much higher than that of Mt.

3.3. TG/DSC Characterization. The TG/DSC curves of Mt and MDOMBAC are shown in Figure 3. The DSC curves of Mt show that the first endothermic valley appears at $98.3^{\circ} \mathrm{C}$ for the loss of the physically adsorbed water and the second endothermic valley appears at $153.9^{\circ} \mathrm{C}$ corresponding to the loss of the interlayer water. About $5.3 \%$ of weight loss is shown in TG curve of Mt. With the increase of temperature, the third endothermic valley appears at $689^{\circ} \mathrm{C}$ with $5.26 \%$ of weight loss, which is due to the dehydroxylation. Comparatively, the TG/DSC curves of MDOMBAC show that there are only one endothermic valley at $73.1^{\circ} \mathrm{C}$ for the loss of physically adsorbed water and interlayer water, because of the less moisture content caused by hydrophobicity after organic intercalation. Between 400 and $700^{\circ} \mathrm{C}$, a great exothermic
TABLE 2: The structure characteristics of Mt and MDOMBAC.

\begin{tabular}{lccc}
\hline Sample & $S_{\text {BET }}\left(\mathrm{m}^{2} / \mathrm{g}\right)$ & $V_{\text {total }}\left(\mathrm{cm}^{3} / \mathrm{g}\right)$ & $D_{p}(\mathrm{~nm})$ \\
\hline $\mathrm{Mt}$ & 41.217 & 0.087 & 7.854 \\
MDOMBAC & 147.745 & 0.276 & 9.121 \\
\hline
\end{tabular}

peak appears due to the burning of organism and then a lot of heat releases and about $43.73 \%$ of weight loss occurs, which is close to the adding quantity of DOMBAC. When the temperature rises continuously, the decomposition of MDOMBAC occurs with $1.32 \%$ of weight loss [20, 21]. The results obtained show that the dosage of DOMBAC is proper and the structure of MDOMBAC is stable below $400^{\circ} \mathrm{C}$, confirming that DOMBA ions added are bound in the interlayer space of MDOMBAC [22].

3.4. $\mathrm{N}_{2}$ Adsorption/Desorption. The $S_{\mathrm{BET}}, V_{\text {total }}$, and $D_{p}$ of Mt and MDOMBAC were measured, and all of the data are summarized in Table 2. The $\mathrm{N}_{2}$ adsorption/desorption isotherms and pore size distribution curves of samples are shown in Figure 4. It shows that isotherms exhibit Type II behaviors according to the IUPAC classification [23], and the $D_{p}$ of samples was about $7-9 \mathrm{~nm}$, characteristics of major mesoporous adsorbents, seen from the formed hysteresis loop which fits to the fourth type of hysteresis loop (H4), indicating slit pores formed from layer structure [23]. The main differences obtained from the isotherms are that the $S_{\mathrm{BET}}$ and $V_{\text {total }}$ of MDOMBAC are significantly larger than that of $\mathrm{Mt}$, indicating the different pore structure of MDOMBAC with more mesoporous. It can be attributed to the "pore prop" effect; meanwhile, the incorporation of DOMBA ions and $\mathrm{Mt}$ in the interlayer area forms a more porous intercalation compound [24]. The results demonstrate that, with the special pore structure formed by intercalation, MDOMBAC obtains a higher adsorption capacity of ZEA than that of Mt.

3.5. FTIR Characterization. The FTIR spectra of Mt and MDOMBAC are shown in Figure 5. The spectra of Mt shows that the stretching vibration band of $\mathrm{Al}-\mathrm{OH}-\mathrm{Al}$ group at octahedral layer is at about $3668 \mathrm{~cm}^{-1}$ and its bending vibration band is at $915 \mathrm{~cm}^{-1}$. The band at around $3430 \mathrm{~cm}^{-1}$ is the stretching vibration of interlayer water molecule and at $1639 \mathrm{~cm}^{-1}$ is the bending vibration. The two bands are observed at $1077 \mathrm{~cm}^{-1}$ and $1031 \mathrm{~cm}^{-1}$ in the Si-O-Si stretching vibration region and the former is stronger; the band at $463 \mathrm{~cm}^{-1}$ is the bending vibration of Si-O-Si. The weak band at $525 \mathrm{~cm}^{-1}$ is bending vibration of $\mathrm{Si}-\mathrm{O}-\mathrm{Al}$ and the band at $834 \mathrm{~cm}^{-1}$ is due to stretching vibration of $\mathrm{Al}^{\mathrm{IV}}$ tetrahedra, when replacing Si with $\mathrm{Al}$ [25]. After intercalation with DOMBAC, three new bands are observed at $1473 \mathrm{~cm}^{-1}$, $2921 \mathrm{~cm}^{-1}$, and $2852 \mathrm{~cm}^{-1}$ which are bending vibration, asymmetrical stretching vibration, and symmetrical stretching vibration of $\mathrm{CH}$ due to the introduction of DOMBA ions [26]. These results suggest that Mt and DOMBA ions have been combined together, which results in more active sites on MDOMBAC and higher adsorption capacity of ZEA. 


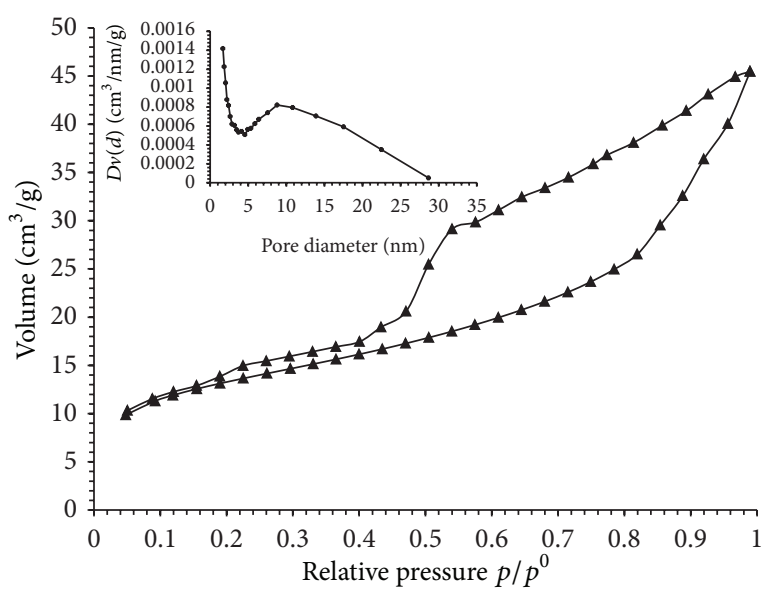

(a)

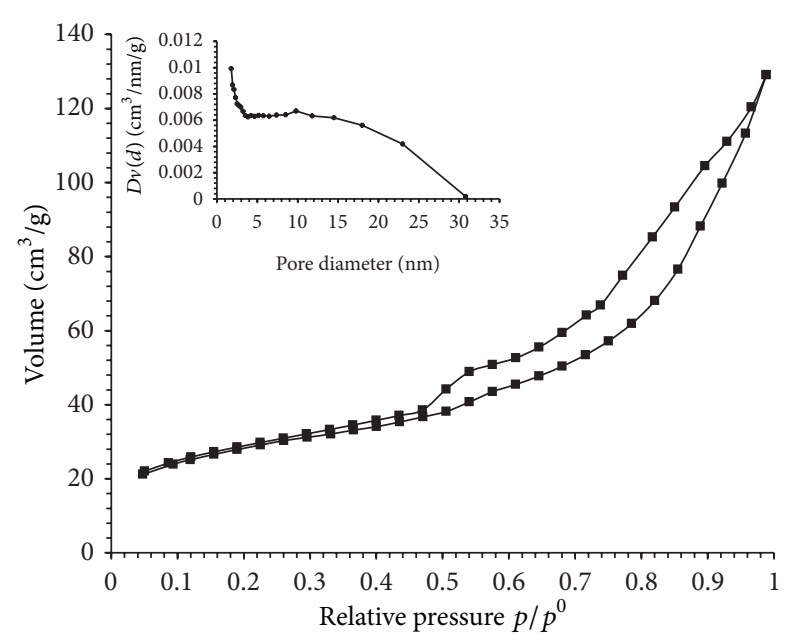

(b)

FIgURE 4: The $\mathrm{N}_{2}$ adsorption/desorption isotherms of (a) Mt and (b) MDOMBAC and the insert figures are pore size distribution curves.

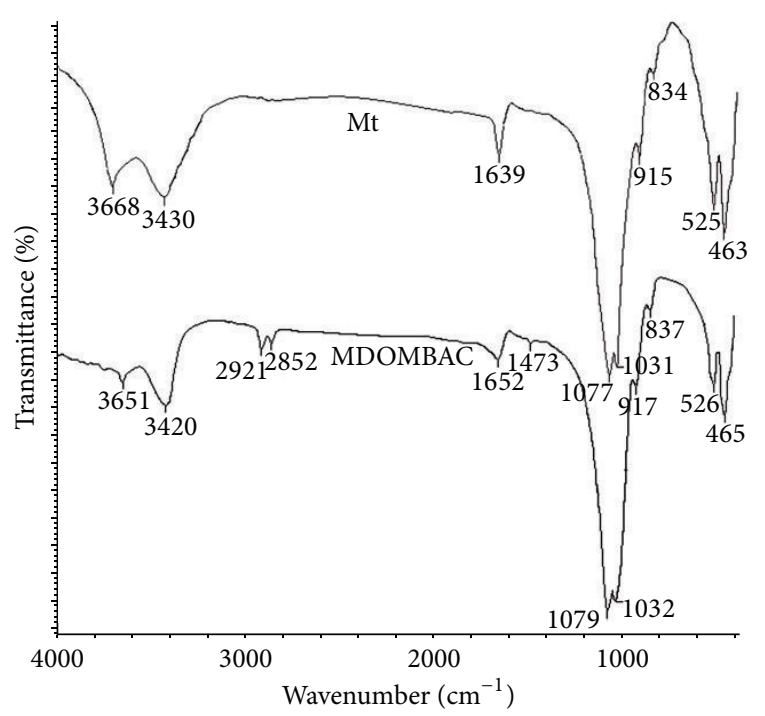

Figure 5: FTIR spectra of Mt and MDOMBAC.

3.6. Adsorption Isotherms. It is important to analyze the isotherm data so as to investigate the mechanism of ZEA adsorption by $\mathrm{Mt}$ and MDOMBAC, and the results can help realize better design to remove ZEA from the foods for human and animal. Therefore, two main models of adsorption isotherm were analyzed at $\mathrm{pH}=2$, Langmuir and Freundlich, respectively [27, 28].

The Langmuir adsorption isotherm assumes that adsorption occurs at specific homogeneous sites inside the adsorbent. The adsorption data were fitted to the linear form of Langmuir adsorption model (1) and the adsorption isotherm was obtained by plotting the particular adsorption $\left(C_{e} / C\right)$ against the equilibrium concentration of ZEA $\left(C_{e}\right) . C_{e}$ is the equilibrium concentration of ZEA which means the final concentration $(\mathrm{mg} / \mathrm{L})$ of ZEA in the solution after adsorbed, $C_{m}$ is the maximum adsorbance of the sorbent, $C$ is the amount of ZEA adsorbed by the adsorbent at equilibrium, and $K$ is a Langmuir constant related to the adsorption energy:

$$
\frac{C_{e}}{C}=\frac{1}{C_{m} K}+\frac{C_{e}}{C_{m}} .
$$

Secondly, the adsorption data were fitted to the linear form of Freundlich adsorption model:

$$
\ln C=\ln K_{f}+\frac{1}{n_{f}} \ln C_{e},
$$

where $K_{f}$ is Freundlich constant related to adsorption intensity and $n_{f}$ is constant related to adsorption intensity as well; $C$ and $C_{e}$ denote adsorbance of ZEA and equilibrium concentration of ZEA, respectively. Freundlich equation is an exponential variation in site energies and it is assumed that the adsorbent has heterogeneous energy distribution of active sites. Theoretically, Freundlich model is suitable for use with heterogeneous surfaces and with this expression; an infinite amount of adsorption can occur.

The absorption isothermal curves (Figure 6) and all isotherm values (Table 3 ) display that the data of $\mathrm{Mt}$ fit to the Langmuir model much better $\left(R^{2}=0.9997\right)$, whereas the Freundlich model is less appropriate $\left(R^{2}=0.8817\right)$; meanwhile, comparing the $R^{2}$ values of MDOMBAC, the Langmuir model obtains much better fit too, indicating that isotherms of both $\mathrm{Mt}$ and MDOMBAC are consistent with the Langmuir model and conform to monolayer adsorption over a homogenous adsorbent surface. The results show that organic intercalation does not change the adsorption mode. The $C_{m}$ values of $\mathrm{Mt}$ and MDOMBAC shown in Table 3 present that the adsorbance of ZEA on MDOMBAC is higher than that of Mt; as the type of interlayer ions is the key factor for the adsorption $[29,30]$, it indicates that interlayer ions of DOMBA in MDOMBAC have stronger interaction with ZEA than that of sodium ions in Mt. 


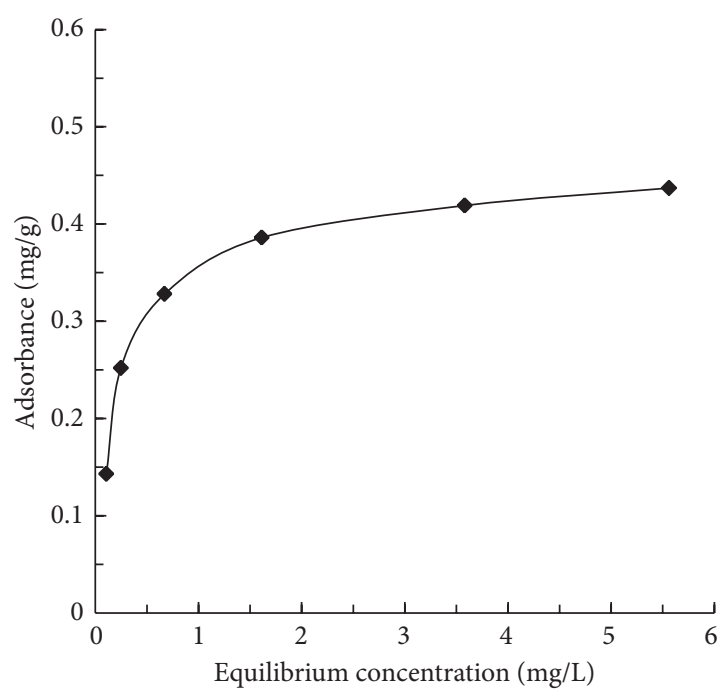

(a)

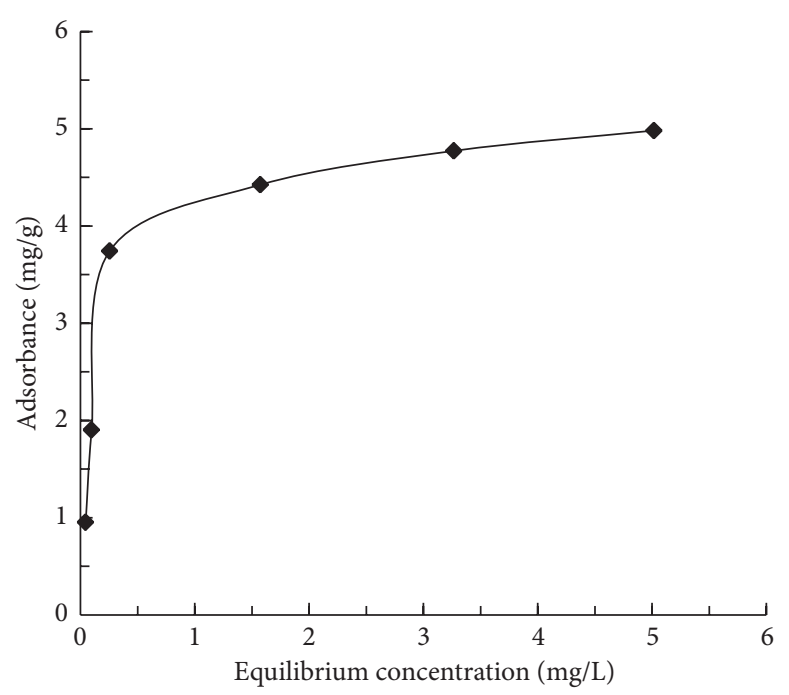

(b)

FIgURE 6: Adsorption isotherms of ZEA onto (a) Mt and (b) MDOMBAC.

TABLE 3: Isotherm parameters for ZEA adsorption onto Mt and MDOMBAC.

\begin{tabular}{lccccr}
\hline \multirow{2}{*}{ Sample } & \multicolumn{3}{c}{ Langmuir } & \multicolumn{3}{c}{ Freundlich } \\
& $C_{m}(\mathrm{mg} / \mathrm{g})$ & $K(\mathrm{~L} / \mathrm{mg})$ & $R^{2}$ & $K_{f}(\mathrm{mg} / \mathrm{g})$ & $n_{f}$ \\
\hline Mt & 0.4529 & 4.1156 & 0.9997 & 0.3140 & 3.8610 \\
MDOMBAC & 5.0761 & 6.6555 & 0.9989 & 3.497 & 0.8817 \\
\hline
\end{tabular}

\section{Conclusions}

The final results demonstrate the adsorption of ZEA onto Mt and organomodified Mt. By the method of intercalation with DOMBAC, an effective adsorbent of MDOMBAC for removing ZEA was prepared, which exhibited the highest adsorption rate of ZEA (93.6\%). Mt and MDOMBAC were characterized by several methods, including XRD, TG/DSC, $\mathrm{N}_{2}$ adsorption/desorption, and FTIR. According to the analysis of results, it can be concluded that the higher adsorption capacity of ZEA on MDOMBAC mainly lies in the factors of greater surface area, higher porosity, much more active sites, and hydrophobicity. Determination of ZEA adsorption isotherms for $\mathrm{Mt}$ and MDOMBAC shows that the ZEA adsorption follows the Langmuir isotherm model and the maximum adsorbance of ZEA on adsorbents was estimated to be $5.0761 \mathrm{mg} / \mathrm{g}$.

Generally speaking, in the practical application, detoxification treatments with MDOMBAC are technically and economically reliable, including (a) the elimination of ZEA, (b) not having any secondary pollution, (c) the protection of nutritive value, and (d) the antibacterial activity. Meanwhile, this adsorbent is cost effective and has high removal efficiency for ZEA from aqueous and organic solutions. Furthermore, the adsorbent is adaptable and stable when applied in different environments, which are the most critical properties for the removal of ZEA with variant concentrations in natural contaminated food. Hence, in order to prevent the hazardous effects of ZEA, Mt intercalation compound with
DOMBAC can be used as the potential adsorbent to prevent mycotoxicosis.

\section{Conflict of Interests}

The authors declare that there is no conflict of interests regarding the publication of this paper.

\section{Acknowledgment}

The study was supported by the Research Funds for the Geologic Survey (1212011120277).

\section{References}

[1] J.-M. Chen, G. Gong, L.-Q. Zhao, and X.-C. Sun, "Determination of cation exchange capacity of expansive soils," Rock and Mineral Analysis, vol. 19, no. 2, pp. 152-154, 2000.

[2] A. Daković, Ž. Sekulić, G. E. Rottinghaus, A. Stojanović, S. Milićević, and M. Kragović, "T-2 toxin adsorption by hectorite," Journal of the Serbian Chemical Society, vol. 74, no. 11, pp. 12831292, 2009.

[3] C. M. Placinta, J. P. F. D’Mello, and A. M. C. MacDonald, "A review of worldwide contamination of cereal grains and animal feed with Fusarium mycotoxins," Animal Feed Science and Technology, vol. 78, no. 1-2, pp. 21-37, 1999.

[4] A. Zinedine, J. M. Soriano, J. C. Moltó, and J. Mańes, "Review on the toxicity, occurrence, metabolism, detoxification, regulations 
and intake of zearalenone: an oestrogenic mycotoxin," Food and Chemical Toxicology, vol. 45, no. 1, pp. 1-18, 2007.

[5] S. Abbès, Z. Ouanes, J. B. Salah-Abbès et al., "The protective effect of hydrated sodium calcium aluminosilicate against haematological, biochemical and pathological changes induced by Zearalenone in mice," Toxicon, vol. 47 , no. 5, pp. 567-574, 2006.

[6] A. Daković, S. Matijašević, G. E. Rottinghaus, V. Dondur, T. Pietrass, and C. F. M. Clewett, "Adsorption of zearalenone by organomodified natural zeolitic tuff," Journal of Colloid and Interface Science, vol. 311, no. 1, pp. 8-13, 2007.

[7] M. D. Lindemann, D. J. Blodgett, E. T. Kornegay, and G. G. Schurig, "Potential ameliorators of aflatoxicosis in weanling/growing swine," Journal of Animal Science, vol. 71, no. 1, pp. 171-178, 1993.

[8] M. A. Abdel-Wahhab, S. A. Nada, and F. A. Khalil, "Physiological and toxicological responses in rats fed aflatoxincontaminated diet with or without sorbent materials," Animal Feed Science and Technology, vol. 97, no. 3-4, pp. 209-219, 2002.

[9] J. Feng, M. Shan, H. Du, X. Han, and Z. Xu, "In vitro adsorption of zearalenone by cetyltrimethyl ammonium bromidemodified montmorillonite nanocomposites," Microporous and Mesoporous Materials, vol. 113, no. 1-3, pp. 99-105, 2008.

[10] J.-M. Chen, G. Gong, L.-Q. Zhao, and X.-C. Sun, "Determination of cation exchange capacity of expansive soils," Rock and Mineral Analysis, vol. 19, no. 2, pp. 152-154, 2000.

[11] J. M. Adams, "Synthetic organic chemistry using pillared, cation-exchanged and acid-treated montmorillonite catalystsa review," Applied Clay Science, vol. 2, no. 4, pp. 309-342, 1987.

[12] J. Bhatt, R. S. Somani, H. M. Mody, and H. C. Bajaj, "Rheological study of organoclays prepared from Indian bentonite: effect of dispersing methods," Applied Clay Science, vol. 83-84, pp. 106114, 2013.

[13] W. Zhang, J. Ye, Y. Wang, H. Wang, Y. Wang, and Y. Li, "Pore structure and surface fractal characteristics of calcium silicate hydrates contained organic macromolecule," Journal of the Chinese Ceramic Society, vol. 34, no. 12, pp. 1497-1502, 2006.

[14] J. Matusik and Z. Kłapyta, "Characterization of kaolinite intercalation compounds with benzylalkylammonium chlorides using XRD, TGA/DTA and CHNS elemental analysis," Applied Clay Science, vol. 83-84, pp. 433-440, 2013.

[15] S. L. Lemke, P. G. Grant, and T. D. Phillips, "Adsorption of zearalenone by organophilic montmorillonite clay," Journal of Agricultural and Food Chemistry, vol. 46, no. 9, pp. 3789-3796, 1998.

[16] M. Sabater-Vilar, H. Malekinejad, M. H. J. Selman, M. A. M. van der Doelen, and J. Fink-Gremmels, "In vitro assessment of adsorbents aiming to prevent deoxynivalenol and zearalenone mycotoxicoses," Mycopathologia, vol. 163, no. 2, pp. 81-90, 2007.

[17] A. Daković, M. Tomašević-Canović, V. Dondur, G. E. Rottinghaus, V. Medaković, and S. Zarić, "Adsorption of mycotoxins by organozeolites," Colloids and Surfaces B, vol. 46, no. 1, pp. 20-25, 2005.

[18] N. D. Hutson, D. J. Gualdoni, and R. T. Yang, "Synthesis and characterization of the microporosity of ion-exchanged $\mathrm{Al}_{2} \mathrm{O}_{3}$ pillared clays," Chemistry of Materials, vol. 10, no. 11, pp. 37073715, 1998.

[19] S. Abbès, Z. Ouanes, J. B. Salah-Abbès et al., "The protective effect of hydrated sodium calcium aluminosilicate against haematological, biochemical and pathological changes induced by Zearalenone in mice," Toxicon, vol. 47, no. 5, pp. 567-574, 2006.
[20] D. Krajišnik, A. Daković, M. Milojević et al., "Properties of diclofenac sodium sorption onto natural zeolite modified with cetylpyridinium chloride," Colloids and Surfaces B, vol. 83, no. 1, pp. 165-172, 2011.

[21] M. Majdan, S. Pikus, Z. Rzączyńska et al., "Characteristics of chabazite modified by hexadecyltrimethylammonium bromide and of its affinity toward chromates," Journal of Molecular Structure, vol. 791, no. 1-3, pp. 53-60, 2006.

[22] H.-P. He, Z. Ding, J.-X. Zhu et al., “Thermal characterization of surfactant-modified montmorillonites," Clays and Clay Minerals, vol. 53, no. 3, pp. 287-293, 2005.

[23] K. S. W. Sing, D. H. Everett, R. A. W. Haul et al., "Reporting physisorption data for gas solid systems with special reference to the determination of surface area and porosity," Pure and Applied Chemistry, vol. 57, no. 4, pp. 603-619, 1985.

[24] W. Zhang, J. Ye, Y. Wang, H. Wang, Y. Wang, and Y. Li, "Pore structure and surface fractal characteristics of calcium silicate hydrates contained organic macromolecule," Journal of the Chinese Ceramic Society, vol. 34, no. 12, pp. 1497-1502, 2006.

[25] S. Witkowski, Z. Sojka, K. Dyrek et al., "Infra-red studies of ammoniation of pillared montmorillonites," Clay Minerals, vol. 35, no. 2, pp. 345-355, 2000.

[26] U. Díaz, J. A. Vidal-Moya, and A. Corma, "Synthesis and characterization of hybrid organozeolites with high organic content," Microporous and Mesoporous Materials, vol. 93, no. 13, pp. 180-189, 2006.

[27] I. Langmuir, "The constitution and fundamental properties of solids and liquids. Part I. Solids," The Journal of the American Chemical Society, vol. 38, no. 11, pp. 2221-2295, 1916.

[28] H. M. F. Freundlich, "Über die adsorption in löungen," Zeitschrift für Physikalische Chemie, vol. 57, pp. 385-470, 1906.

[29] L. Zeng, S. P. Wang, X. Q. Peng, J. Geng, C. Chen, and M. $\mathrm{Li}$, "Al-Fe PILC preparation, characterization and its potential adsorption capacity for aflatoxin B1," Applied Clay Science, vol. 83-84, pp. 231-237, 2013.

[30] T. D. Phillips, A. B. Sarr, and P. G. Grant, "Selective chemisorption and detoxification of aflatoxins by phyllosilicate clay," Natural Toxins, vol. 3, no. 4, pp. 204-213, 1995. 

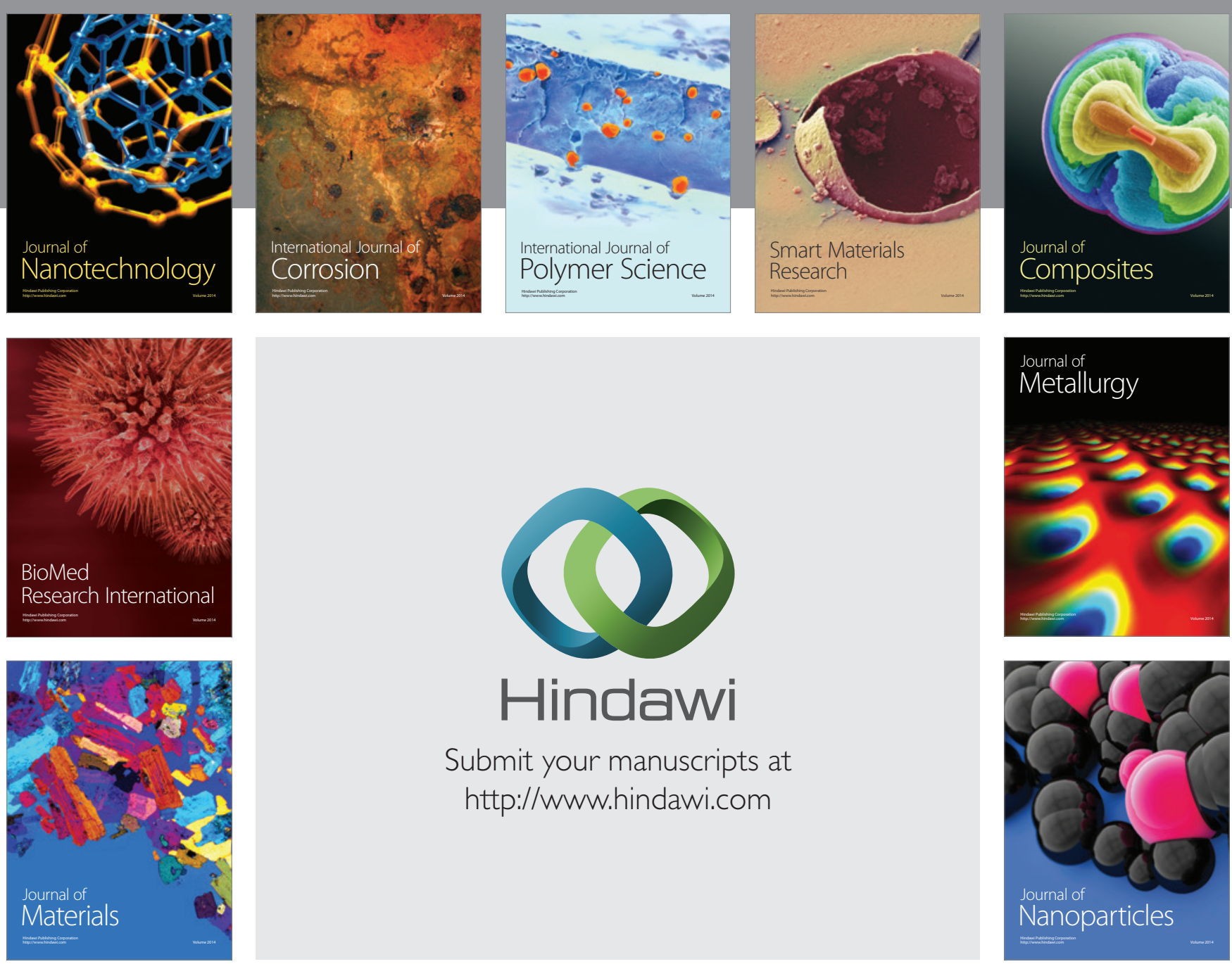

Submit your manuscripts at http://www.hindawi.com
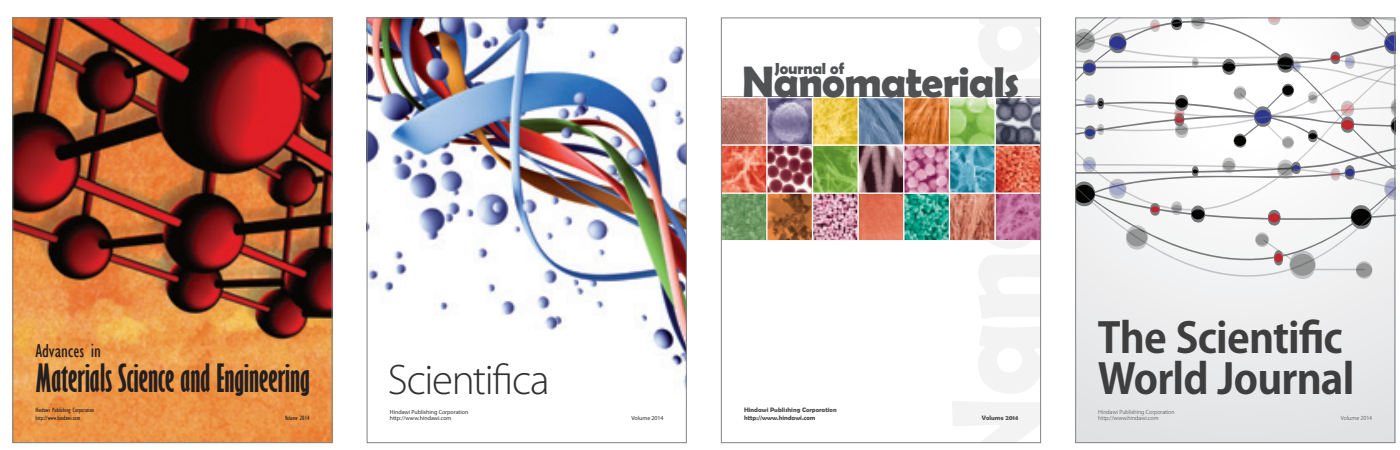

\section{The Scientific World Journal}
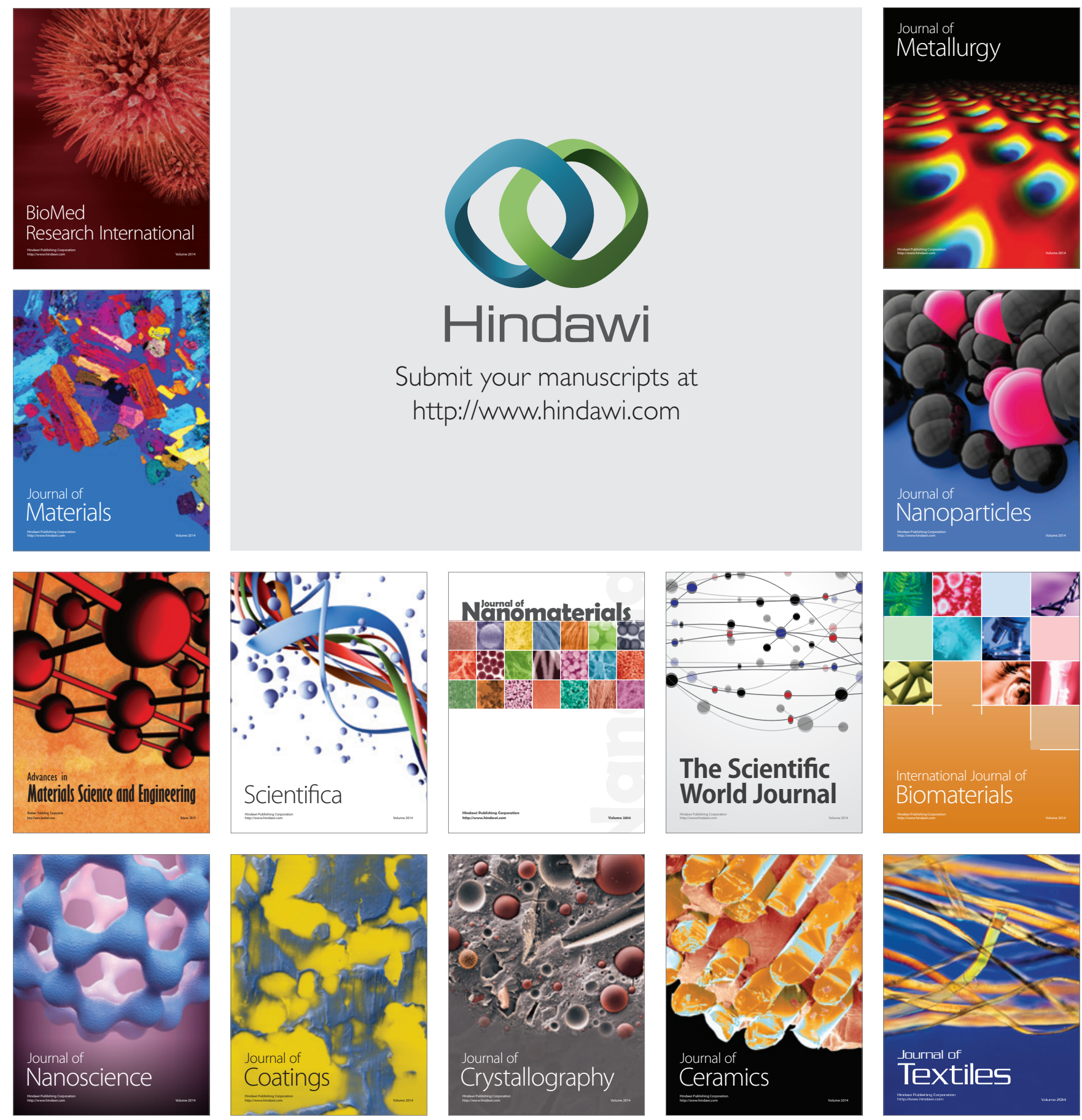